\title{
PRODUCTION LEAD TIME AS A TOOL TO MEASURE LEANNESS LEVEL
}

\author{
[Výrobní čas jako nástroj k měření úrovně štíhlosti] \\ Michal Medonos ${ }^{1}$, Marie Jurová ${ }^{2}$ \\ ${ }^{1}$ Faculty of Business and Management, Brno University of Technology, Kolejni 2906/4, 61200 Brno \\ Email: medonos7@gmail.com \\ ${ }^{2}$ Faculty of Business and Management, Brno University of Technology, Kolejní 2906/4, 61200 Brno \\ Email: jurova@fbm.vutbr.cz
}

\begin{abstract}
Measurement of lean production is a topic which isn't too often mentioned by authors focused on lean methodology. We have decided to focus on this gap, because we believe that it is important part of successful implementation of lean production. We have created a simple method related to evaluation of leanness of production processes using production lead time. Based on our survey we could prove our method in real companies, using real data and parameters of their production lines. We asked responsible persons in addressed companies for an interview during which we filled in our questionnaire. Results brought us interesting insights into the current situation of production companies located mainly in the Czech Republic, but often with the international background. Based on it we understand that there is a lot of opportunities for improvements including higher adoption of lean production. Also, we have realized that our methodology related to measurement of leanness level of production is a tool, which can support it.
\end{abstract}

Keywords: lead time, lean manufacturing, Little's Law, performance measurement, production management.

JEL classification: M11

Received: 26.3.2020; Reviewed: 31.3.2020; 28.4.2020; Accepted: 9.9.2020

\section{Introduction}

In a modern management world, it is very important to measure the performance of a company and efficiency of all processes. In production companies, value added is created by processes in a production. Without an optimized production system, a company cannot be successful on global markets. Lean production is a popular methodology and tool how to gain advantage over others. However, it is a complex approach bringing a lot of changes to the company culture and its habits. Unfortunately, successful implementation is not a matter of course yet. Lots of skills and experiences are needed for this process to prevent failure, which happened to many companies before.

There are many ways of how to increase probability of successful implementation. We believe that an important tool is a measurement of efficiency and progress of this process. To have a benchmark, we have to measure and evaluate the current state of the situation. Based on that benchmark, we can design proper implementation and set the targets. And then we can track the whole process, measure the progress and decide if the whole activity was successful and the production achieved its target to be lean.

We have created a method how to measure lean production based on production lead time. To evaluate this method, we conducted a survey to check it in real production companies. This article is a summary of the first results gained by our survey. We describe here shortly the theoretical background. Then we explain our methodology and the questionnaire that we used 
in our survey. Last chapters are focused on evaluation of results from the survey and discussion about them.

\section{Materials and Methods}

At the beginning, an explanation of basic terms like lean production (LP) and leanness is needed. Then a short literature research about possible ways how to measure lean production are listed. Finally, we describe our survey which we conducted to evaluate our method.

\section{Lean production}

First it is needed to define what Lean production is. There does not exist any standardized definition. However, there are the most common definitions created by other authors: Lean production can be described as the systematic elimination of waste (Liker 2004, p. 28-29); Lean production is an integrated socio-technical system whose main objective is to eliminate waste by concurrently reducing or minimizing supplier, customer, and internal variability (Shah and Ward 2007, p. 791); Lean production is a manufacturing strategy, which strives to minimize waste and thereby increase efficiency (Hofer et al. 2012) or lean production is a strategy or philosophy that promotes the use of practices, such as kanban, total quality management and just-in-time, to minimize waste and enhance firm performance (Womack et al. 1990). We understand that the Lean production is a system of tools, which are used to eliminate waste, where waste is caused by variability, which occurs in the company processes. We must understand that it is a strategy that influences the whole company and even is closely connected with company culture. This definition sounds quite clear, but it is rather general. Every author highlights different parts of these definitions and focuses their research and papers on different matters.

\section{Leanness}

A term used for measurement of LP is "leanness". Similar to definition of lead production, there are more definitions of this term. For purposes of this article we will identify ourselves with definition of Wan and Frank Chen (2008, p. 6569): Leanness level refers to the performance level of a value stream compared with perfection. Therefore, a leanness measure shows "how lean" the system is. The leanness level of a system can be defined and measured by comparing the current state with the worst case and the perfect case. Thus, the level of leanness can be quantified (Anvari et al. 2013). Naylor with colleagues (1999) use "leanness" to describe the process of realizing lean principles while introducing the concept of "leagility". "Leanness" refers to the degree of the adoption and implementation of lean philosophy in the organization (Wong et al. 2014), (Comm and Mathaisel 2000). The term "total leanness" was used by McIvor (2001) to imply a perfectly lean state of several key dimensions of lean supply.

\section{Measurement of leanness}

Lean metrics are performance measures that are used to track the effectiveness of lean implementation (Anvari et al. 2013, p. 665). There is no universal and standardized methodology to evaluate LP. To measure LP, we can use more different approaches. Basically we can divide methods for assessing of leanness into two types, qualitative and quantitative.

The first group - qualitative tools, are based on surveys, a checklist and other forms of getting needed data about companies. These methods are quite subjective, because people knowing the measured company are asked about the status of processes in the company and adoption of lean tools. Then the answers are compared to the generally recognized optimal state. The requested 
data, way of its analyzing and evaluation towards the level of leanness differs based on used methodology.

One of the most popular tools is the Lean Enterprise Self-Assessment Tool developed by lean aerospace initiative at MIT. The model is divided into three sections: Enterprise transformation/leadership, Lifecycle process and Enabling infrastructure. Many authors are expanding and adjusting this model. For example, Sanchez and Perez (2001) who developed a checklist with 36 criteria in 6 groups. Pavnaskar with his team (2003) created a classification scheme for evaluation of 101 lean production tools. And they state, that it is possible to use it for evaluation of problems in production too. Various lean assessment surveys have also been conducted by lean practitioners and researchers to assess the leanness (Karlsson and Ahlstrom 1996), (Soriano-Meier and Forrester 2002), (Fullerton and Wempe 2009). Majority of lean assessment tools provide just a qualitative analysis and do not provide any clear direction of where the improvement efforts should be directed (Srinivasaraghavan and Allada 2006, p. 1159).

The second group are quantitative methods. In comparison to qualitative surveys, quantitative metrics and models provide better leanness score (Karim and Arif-Uz-Zaman 2013, p. 173). Mainly these methods use data from the company information system, financial reports and other data sources. They involve techniques of an overall evaluation of the system. For example, Wan et al. (2007) measured the overall leanness by the VSM (Value Stream Mapping) considering cost, time and output values. Srinivasaraghavan and Allada (2006) have measured leanness by calculating the Mahalanobis distance between the current state of the system and the benchmarking performance. In that case, other companies in the market are taken as a benchmark. The outcome depends heavily on the quality of the benchmark. Fullerton and Wempe (2009) and Agus and Hajinoor (2012) used Structural Equation Modelling (SEM) to establish the relationship between different lean tools and lean production performance. They conducted several surveys to validate the relationships.

Other methods evaluate only specific aspects of the leanness. They comprise the Manufacturing Cycle Efficiency (MCE) index, which represents leanness level in terms of time-based performance and its modification from Fogarty (1992) the Value Added Efficiency (VAE) index to assess leanness from value-added performance perspective. In these methods valueadding time is compared with total cycle time, respectively total manufacturing time with total run time, to show the efficiency of a manufacturing process. Swamidass (2007) used the ratio of total inventory to sales as a general performance index to analyze over 14,000 firms. Eroglu and Hofer (2011) used the Empirical Leanness Indicator (ELI) for measuring inventory leanness. This indicator measures a firm's deviation from the size adjusted within-industry average inventory levels which represents the level of inventory leanness of the company. $\mathrm{Wu}$ and Wee (2009) measured overall equipment effectiveness as a leanness measure.

The last part of methods presents combination of qualitative and quantitative methods. In this case, were explored various operational research techniques to measure leanness, such as using the Data Envelopment Analysis (DEA) (Wan and Frank Chen 2008). Some researchers used fuzzy logic algorithm to measure the manufacturing leanness, since leanness can be measured considering quantitative as well as qualitative indicators with this algorithm (Bayou and Korvin 2008), (Vinodh and Balaji 2011), (Behrouzi and Wong 2011). And Detty and Yingling (2000) have utilized simulation models with several performance metrics to quantify leanness level. 


\section{Production lead time}

We have developed measurement of leanness based on production lead time, which we take as the "key" measure of leanness (Medonos and Jurová 2017). Short lead times and lead time reduction is such a basic tool in LP that you find it to be a strong measure of leanness (Naderi et al. 2009). Although lead time is quite a simple indicator, it represents a strong tool revealing the level of LP. From Little's Law (Little 2004), it is obvious that there is a direct correlation between lead time and WIP. Here WIP represents one of the most common forms of buffers. Buffers are created to cover variability, which is a source of inefficiency of the process. Long lead times represent a high level of WIP, which means a high level of buffers covering big variability and inefficiency of the production. One of the main characteristics of lean production is to decrease the inefficiency. From this point of view, short lead times represent a lower level of variability, a lower need of buffers (stocks) and pointing out the high level of leanness.

Today practically all modern companies have some ERP system, which allows them to have a good data basis for an analysis of production lead times. Then the question is how to set the goal. We need to be able to compare different material flows (production processes) or even different companies. Wan and Frank Chen (2008, p. 6572) stated that ideally a lean manufacturing system runs with one-piece flow without interruption - no buffers, no stocks. Based on it we can use one-piece flow as an ideal benchmark. That means performance of the flow of one piece represents an ideal state, which we set as a goal for implementation and all initiatives should lead to achieve it. It was already Toyota who set one-piece flow as the top level of LP. We can calculate theoretically achieved lead time in a case of one-piece flow with no interruption and compare it with the actual cycle time in a production. The difference shows the level of leanness and the potential for improvement.

\section{Survey}

To check whether production lead time can be used as a measurement of production leanness, we carried our survey in real production companies. The aim was to get the data on which we will be able to calculate leanness level of production. When we calculated the leanness, then we could compare it with a level of adoption of basic lean tools. This comparison showed us how the leanness calculation based on production lead time is corresponding to the level of implementation of LP measured by a common qualitative method.

For that reason, we have created our questionnaire. This questionnaire consisted of 3 parts. The first part was a company identification. Here questions about name of company, contact identification, industry sector, size of company and location of company are placed. Data from this part was used for categorization of each company. The second part consisted of qualitative questions about the level of adoption of 10 most popular lean tools. They are: 5S - Organized workplace, SMED - Quick change-over, Pull system, Kaizen - continuous improvement, Visualization in the workshop, TPM - Total productive maintenance, TQM - Total quality management, Poka-yoke - mistake-proof operations, VSM - Value Stream Mapping and Standardized work. For each tool we use 3 level scale: "Fully implemented", "Partially implemented", "Not implemented". As an attachment detailed description of each level of each tool was provided as a clue. Data from this part was used as a base for comparison and evaluation of our calculation. Finally, the third part consists of quantitative questions about parameters of chosen production line needed for calculation of the leanness by our method. Here questions about current production time and level of work-in-process took place. Followed by questions for calculation - number of operations, operation time for 1 piece, shift regime, OEE, size of batch, daily requested output, changeover time, transportation time, etc. 
To fill out our questionnaire we used interviews with responsible persons in each company, who were able to answer our questions (production managers, logistics managers, lean specialists, etc.). We have focused on production companies mainly on the Czech market, but during our survey we were able to get data from plants from other countries too. First interview took place in 2016, based on which validation of survey was made. Next interviews and data collection followed mainly in 2018 .

\section{Results}

At the moment of writing this article we have results from 24 companies, from which 7 have local presence only on one market and 17 are international companies. 11 companies are large with more than 500 employees, 12 companies are medium-sized with 250-500 employees and there is only one small company with less than 50 employees. 10 companies are from the building sector, 6 are automotive sector companies, 6 engineering companies and one is without any specified sector.

See the table 1 for the results of adoption of the TOP 10 lean tools. The tool with the highest implementation rate is the Pull system which was fully implemented in $50 \%$ of measured companies. The next tool in an order was Standardization, followed by $5 \mathrm{~S}$, Visualization and TQM. On the other side, the least implemented tool is Poka-yoke. In total, the average use of the TOP 10 lean tools in our 24 companies was almost 56,5\%.

Table 1: Table with results of TOP 10 lean tools

\begin{tabular}{|l|c|c|c|}
\hline Tool & Not implemented & Partialy implemeted & Fully implemented \\
\hline $5 S$ & 2 & 13 & 9 \\
\hline SMED & 8 & 9 & 7 \\
\hline Pull & 4 & 8 & 12 \\
\hline Kaizen & 5 & 11 & 8 \\
\hline Visualization & 2 & 13 & 9 \\
\hline TPM & 6 & 11 & 7 \\
\hline TQM & 3 & 12 & 9 \\
\hline Poka-yoke & 7 & 15 & 2 \\
\hline VSM & 8 & 8 & 8 \\
\hline Standardization & 5 & 9 & 10 \\
\hline
\end{tabular}

Source: Own survey

For each company in a survey, we obtained the data needed for our calculations of their leanness level from their production line based on production lead time. Then for each company, we did the calculation. Resulted percentage values mean that the closer the value is to $100 \%$, the leaner the company is. The average value of all 24 companies was $62,8 \%$, where $25 \%$ of companies have leanness level higher than $80 \%$. Then $29 \%$ of companies between $50 \%$ and $80 \%$ and $46 \%$ companies lower than $50 \%$.

Current average lead time of measured lines was 5,1 working days. Our methodology enables us to calculate potential lead time when full implementation of lean production would take place. This potential lead time was 2,65 working days in average. But there were even companies with current lead time 15 working days and potential lead time was 5,2 working days (10 days potential reduction).

If we compare companies with high level of implementation of lean tools with companies with lower level, we can find differences in a complexity of approach towards lean manufacturing. Every company use at least some tool from the list. But only the best are using most of them or all of them at once. For example, VSM as an important tool for optimization of production 
times wasn't implemented in a third of companies at all. This supports statements of many authors that lean manufacturing is a complex approach towards production optimization.

\section{Discussion}

The results of our survey showed us two interesting facts. First, the level of implementation of LP is not on such that high level, as we had expected. We can find differences between the size of companies, sectors, and internationality of companies. Generally, we can say that bigger, international companies in the automotive sector have a higher level of LP adoption than smaller, local companies from other sectors. But even in our list of companies, we can find exceptions. From our interviews, we can say that it is mainly caused by position on a market and current situation in a company. For example, the automotive sector is driven by a few automobile companies which have high expectations from their suppliers in terms of efficiency, quality, costs, etc. Also, companies from this sector have the longest experience with LP methods. On the other hand, companies which are not forced by their customers or their market to implement LP tools, and their performance is sufficient for their owners, they are not under such a pressure to adopt LP. At that moment, it is more about management skills and experience of how much they use LP tools.

The second output is a comparison of results from our questions about adoption of LP tools with results gained from our calculation of the leanness level using production lead time. LP tools adoption with the average level of $56,5 \%$, and the lead time leanness level of $62,8 \%$ are very close results and they are showing us that both methodologies provide us similar results. When we compared results of both methods for all companies in our survey, we got the value of the correlation coefficient of 0,8 . Based on the comparison, we can say that the measurement of lean production based on production lead time can be used for evaluation of efficiency of production lines and the level of adoption of LP tools.

Of course, there are a few limitations. Use of only one metric to evaluate production performance is a simplification. We cannot use this method for any complex evaluation of a company as a whole. This method is strictly focusing on evaluation of a production process. Other company processes such as sales, marketing, R\&D and others are not covered by this. But for measurement of production, it is possible to indicate quite quickly and easily the current state of efficiency and potentials for improvement. And that was our target.

Another limitation is that at this moment we put forward our conclusions with data acquired only from 24 companies. For any generalization, the number is too low. We are working on data collection from other companies, but we have realized that it is not easy to obtain the data from the companies. One problem is even to connect with the company and meet the responsible person. The second problem is that even though our calculation is based on parameters, which should be easy to get from company information system, many companies do not work with this type of data. Once the reporting system is prepared for this data collection, there is no problem to repeat the calculation and measure all production lines and track the improvements.

Even though there are some limitations we believe that our methodology has potential for being used in practice. It is able to evaluate current efficiency of a production process based on objective data from information systems. It is able to compare and contrast different production lines and even different companies from different sectors. Moreover, it is capable to calculate the future potential for improvement and set targets for production management. It can be used as a one of production/company Key Performance Indicators. 


\section{Conclusion}

As we mentioned in our literature review, there are many ways of how to measure LP. We prefer to use those which are based on objective data rather than using subjective evaluation. For that reason, we have created a measurement of lean production based on production lead time, which we afterwards tested by a survey using a questionnaire. Preliminary results from 24 production companies are showing that our method is successful and usable for practical purposes. There are a few limitations caused by simplifying the calculation as much as possible. However, we believe that the benefits overcharge the limitations. In the future we would like to involve more companies in our survey to check universal use of our methodology. We have some positive reactions on usage of our methodology as a production KPI and to use it as a comparison of different production lines in a company or even as a benchmark between different companies. If this is implemented, then our target will be achieved.

\section{References}

[1] AGUS, A. and M. S. HAJINOOR, 2012. Lean production supply chain management as driver towards enhancing product quality and business performance. International Journal of Quality \& Reliability Management, 29(1): 92-121. ISSN: 0265-671X.

[2] ANVARI, A., N. ZULKIFLI and R. M. YUSUFF, 2013. A dynamic modelling to measure lean performance within lean attributes. The International Journal of Advanced Manufacturing Technology, 66(5-8): 663-677. ISSN: 0268-3768.

[3] BAYOU, M. E. and A. DE KORVIN, 2008. Measuring the leanness of manufacturing systems: a case study of Ford Motor Company and General Motors. Journal of Engineering \& Technology Management, 25(4): 287-304. ISSN: 0923-4748.

[4] BEHROUZI, F. and K. Y. WONG, 2011. Lean performance evaluation of manufacturing systems: a dynamic and innovative approach. Procedia Computer Science, 3: 388-95. ISSN: $1877-0509$.

[5] COMM, A. R. and D. F. X. MATHAISEL, 2000. A paradigm for benchmarking Lean initiatives for quality improvement. Benchmarking: An International Journal, 7(2): 118127. ISSN: 1463-5771.

[6] DETTY, R. B. and J. C. YINGLING, 2000. Quantifying benefits of conversion to lean manufacturing with discrete event simulation: a case study. International Journal of Production Research, 28(2): 429-445. ISSN: 0020-7543.

[7] EROGLU, C. and C. HOFER, 2011. Lean, leaner, too lean? The inventory-performance link revisited. Journal of Operations Management, 29(4): 356-369. ISSN: 0272-6963.

[8] FOGARTY, D. W., 1992. Work in process: performance measures. International Journal of Production Economics, 26(1): 169-172. ISSN: 0925-5273.

[9] FULLERTON, R. R. and W. F. WEMPE, 2009. Lean manufacturing, non-financial performance measures, and financial performance. International Journal of Operations \& Production Management, 29(3): 214-40. ISSN: 0144-3577.

[10] HOFER, C., C. EROGLU and A. ROSSITER HOFER, 2012. The effect of lean production on financial performance: The mediating role of inventory leanness. International Journal of Production Economics, 138(2): 242-253. ISSN: 0925-5273.

[11] KARLSSON, C. and P. AHLSTROM, 1996. Assessing changes towards lean production management. International Journal of Operations and Production Management, 16(2): 24-41. ISSN: 0144-3577. 
[12] KARIM, A. and K. ARIF-UZ-ZAMAN, 2013. A methodology for effective implementation of lean strategies and its performance evaluation in manufacturing organizations. Business Process Management Journal, 19(1): 169-196. ISSN: 1463-7154.

[13] LIKER, J., 2004. The Toyota Way: 14 Management Principles from the World's Greatest Manufacturer. McGraw-Hill, NY, ISBN: 8601300053356.

[14] LITTLE, J. D. C., 1961. A proof for the queuing formula: L=own. Operations Research, 9(3): 383-387. ISSN 0030-364X.

[15] MCIVOR, R., 2001. Lean supply: the design and cost reduction dimensions. European Journal of Purchasing and Supply Management, 7(4): 227-242. ISSN: 1478-4092.

[16] MEDONOS, M. and M. JUROVÁ, 2017. Measuring the level of leanness of productionuse of production lead time. Scientific papers of the University of Pardubice. Series D, Faculty of Economics and Administration. 40/2017: 143-153. ISSN: 1211-555X.

[17] NADERI, B., M. ZANDIEH and S. M. T. FATEMI GHOMI, 2009. Scheduling job shop problems with sequence-dependent setup times. International journal of production research, 47(21): 5959-5976. ISSN: 0020-7543.

[18] NAYLOR, J. B., M. M. NAIM and D. BERRY, 1999. Leagility: integrating the lean and agile manufacturing paradigms in the total supply chain. International Journal of Production Economics, 62(1): 107-118. ISSN: 0925-5273.

[19] SANCHEZ, A. M. and M. P. PEREZ, 2001. Lean indicators and manufacturing strategies. International Journal of Operations \& Production Management, 21(11): 1433-1452. ISSN: 0144-3577.

[20] SHAH, R. and P. T. WARD, 2007. Defining and developing measures of lean production. Journal of Operations Management, 2007, 25(4): 785-805. ISSN: 0272-6963.

[21] SORIANO-MEIER, H. and P. L. FORRESTER, 2002. A model for evaluating the degree of leanness of manufacturing firms. International Journal of Integrated Manufacturing Systems, 13: 104-9. ISSN: 0957-6061.

[22] SRINIVASARAGHAVAN, J. and V. ALLADA, 2006. Application of mahalanobis distance as a lean assessment metric. The International Journal of Advanced Manufacturing Technology, 29(11-12): 1159-1168. ISSN: 0268-3768.

[23] SWAMIDASS, P. M., 2007. The effect of TPS on US manufacturing during 1981-1998: inventory increased or decreased as a function of plant performance. International Journal of Production Research, 2007, 45(16): 3763-78. ISSN: 0020-754.

[24] VINODH, S. and S. R. BALAJI, 2011. Fuzzy logic based leanness assessment and its decision support system. International Journal of Production Research, 49(13): 40274041. ISSN: 0020-754.

[25] WAN, H. D., F. FRANK CHEN and L. RIVERA, 2007. Leanness score of value stream maps. Proceedings of the 2007 Industrial Engineering Research Conference, ISBN: 14244-1529-2

[26] WAN, H. D. and F. FRANK CHEN, 2008. A leanness measure of manufacturing systems for quantifying impacts of lean initiatives. International Journal of Production Research, 46(23): 6567-6584. ISSN: 0020-754.

[27] WOMACK, J., D. JONES and D. ROOS, 1990. The Machine That Changed The World. Rawson Associates, NY, ISBN: 0060974176. 
[28] WONG, W. P., J. IGNATIUS and K. L. SOH, 2014. What is the leanness level of your organization in lean transformation implementation? An integrated lean index using ANP approach. Production Planning and Control, 25(4): 273-287. ISSN: 0953-7287.

[29] WU, S. and H. M. WEE, 2009. Lean supply chain and its effect on product cost and quality: a case study on Ford Motor Company. Supply Chain Management: An International Journal, 14(5), pp. 335-341. ISSN: 1359-8546. 